\title{
Modelling foreign exchange rates: a comparison between Markov-switching and Markov-switching GARCH
}

\author{
Mohd Azizi Amin Nunian, Siti Meriam Zahari, S. Sarifah Radiah Shariff \\ Centre for Statistics and Decision Science, Universiti Teknologi MARA, Malaysia
}

\begin{tabular}{l} 
Article Info \\
\hline Article history: \\
Received Jan 25, 2020 \\
Revised Mar 24, 2020 \\
Accepted Apr 9, 2020 \\
\hline
\end{tabular}

Keywords:

Foreign exchange

Markov-switching

Markov-switching GARCH

regime

Persistent

\begin{abstract}
Foreign exchange rate is important as it determines a country's economic condition. It is used to carry out transfers of purchasing power between two or more countries. Volatility in exchange rates may result in difficulty in decision making especially, in financial sectors as high volatility could increase the risk in exchange rates. Thus, Markov switching model is employed in this study as it is believed to be efficient in handling not only volatilility but also nonlinearity characteristics in exchange rates. The aims of this study are to model the foreign exchange rates using two models; Markov Switching (M-S) models and Markov Switching Generalized Autoregressive Conditional Heteroscedasticity (M-S GARCH) and to compare these two models based on log-likelihood, AIC and BIC criteria. This study used the quarterly data of foreign exchange rates for Singapore Dollar (SGD), Korean Won (KRW), China Yuan Renminbi (CNY), Japanese Yen (JPY) and the US Dollar (USD) against Malaysia Ringgit (MYR) which were collected from Quarter 4, 2006 to Quarter 1, 2018. The findings indicate that Markov Switching is the best model since it has the highest log-likelihood value, and the lowest AIC and BIC values. The results show that JPY and SGD have highly persistent trends on regime 1 with probability values 0.96 and 0.84 , respectively as compared to CNY, KRW and USD, while the latter have high persistent trends on regime 2 with probability values, $0.99,0.95,0.82$, respectively.
\end{abstract}

Copyright () 2020 Institute of Advanced Engineering and Science. All rights reserved.

\section{Corresponding Author:}

S. Sarifah Radiah Shariff, Malaysia Institute of Transport, Universiti Teknologi MARA, Shah Alam, Selangor, Malaysia. Email: radiah@tmsk.uitm.edu.my

\section{INTRODUCTION}

The Asian financial crisis began in Thailand in July 1997 due to the fall of the Thai Baht. This happens because the Thai government lowers its currency value against the US dollar. With respect to a few months of speculative stress that has abolished the official foreign exchange reserves of Thailand, it marked the beginning of a severe financial crisis in most of the East Asian region. Malaysia, the Philippines, and Indonesia also allowed their currencies to weaken significantly in facing market pressures, with Indonesia gradually falling into diverse financial and political crises. The severe stabilize pressure in South Korea brings the country to the default threshold. The crisis was triggered by four major issues that began with dramatic currency and equity declines in Thailand, Indonesia, South Korea and other Asian countries due to lack of foreign exchange $[1,2]$. This is followed by inefficiencies in developing effective mechanisms for allocating 
capital in unstable Asian economies. The third issue was the international crisis between the United States and other countries. The role and operation issues of the International Monetary Fund (IMF), as well as the issue of raising funds to the countries involved, was the last major issue. The first round occurred during the undervalued of the Thai Baht, the Malaysian Ringgit, the Philippine Peso, and the Indonesian Rupiah. However, after the currencies re-stabilize, the second round began when the Taiwanese Dollar, South Korean Won, Singapore Dollar, and Hong Kong Dollar were severely forced down. During this period, the Malaysian government was able to curb their currency by taking drastic initiatives to sell their foreign exchange reserves and raise the interest rates. This has slower down the economic growth and create more attractive securities than equity. There are several models being used in studying the behavior of financial variation inclusive of the exchange rate behaviors [3, 4]. For example, modelling the KLCI stock market using two models; Stochastic Volatility (SV) and Generalized Auto-Regressive Conditional Heteroscedasticity (GARCH) [5].

Early study on the exchange rate behavior by using Markov switching model was conducted by $[6,7]$. They proved that the Markov switching model was a good estimation model for the limited data and they used quarterly data of exchange rate. [8] ran a study on Markov Switching model to describe the behavior of eighteen exchange rates and the results showed that the Markov switching model was a sufficient model to predict the exchange rates. Unfortunately, the model does not produce the best prediction for a random walk. On the other hand, [9] conducted another study to observe the behavior of European Monetary System exchange rates, also by employing the Markov switching model and the exchange rate was volatile. Later, [10] studied the daily exchange rate of three countries against the US dollar by using the Markov switching model. The study concluded that the data were well estimated by the model, however, the out of sample forecast was very poor due to the parameter inconstancy. In addition, [11] examined the ability of the switching regime model to capture the dynamics of foreign exchange rates. The tests showed that the model shifts regimes with independent shifts in mean and variance showing a good fit and accurate forecast variance as compared to other models, eventhough the option price did not demonstrate regime change $[12,13]$ proved that the 2-state Markov switching AR (1) model outperformed two competing models where the real exchange rate was non stationary. They also found out that the existence of different regimes, as in the Markov switching model, was in line with unit roots in real exchange rates. This study was supported by [14], where they employed the Markov switching model to capture three regime shifts in the Malaysian exchange rates against four countries, from the year 1990 to 2005. They concluded that the Markov Shifting model successfully captured the time regime in four series. The results were also supported by [15]. Note that there are other types of Markov regime switching model such MRS-GARCH-N, MRS-GARCH-t and MRSGARCH-GED for a more thorough comparison by incorporating the presence of outliers in the models [16,17].

In contrast, [18] and [19] introduced the Markov Regime Switching ARCH (MRSARCH) model that combines the Markov Switching models $[20,21]$ with the ARCH specification. The MRSARCH model is designed to capture regime change in uncertainty with unobserve state variables after the first Markov Chain order process. Parameters in the ARCH process are allowed to change with respect to different countries. ARCH specifications were used to deal with infinite path dependencies. [22] developed new function of GARCH, fGARCH(1,1) model, by incorporating strictly stationary condition in the model. Current research that discussed on Markov switching models in exchange rates can be found in [23, 24] in which, a comparison between Markov switching and random walk were made in [25]. The findings showed that allowing more regimes can improve forecasting with the former model, though, random walk outperformed the model. The rest of the paper is structured as follows: Section 2 briefly reviews on the Markov switching and Markov switching GARCH models. Section 3 presents the empirical results with the comparisons of both models and Section 4 concludes the paper.

\section{RESEARCH METHOD}

This study employed the quarterly closed price data of foreign exchange rates for China Yuan Renminbi (CNY), US Dollar (USD), Japanese Yen (JPY), Singapore Dollar (SGD) and Korean Won (KRW) which are collected from Quarter 4, 2006 to Quarter 1, 2018. Data were extracted from the Bloomberg terminal. The exchange rate is converted into return series using $y_{t}=100 \times\left[\ln \left(r_{t}\right)-\ln \left(r_{t-1}\right)\right]$, where $r_{t}$ denotes the quarterly exchange rates.

\subsection{Markov switching model}

The Markov switching model is one type of regime switching model that is typically applied on data sets to capture non-linearity in the data generating process as such that the model can capture the asymmetric behaviour of the data across different regime or subsamples. The model was introduced by [18] in which the models represent the dynamic pattern of exchange rates as an unobservable state-dependent process. The standard k-state Markov switching model can be written as: 


$$
y_{\mathrm{t}}=\mu\left(\mathrm{s}_{\mathrm{t}}\right)+\sigma\left(\mathrm{s}_{\mathrm{t}}\right) \varepsilon_{t} \text { with } \varepsilon_{t} \sim N(0,1)
$$

such that,

$$
y_{\mathrm{t}}=\left\{\begin{array}{l}
\mu_{1}+\sigma_{1} \varepsilon_{\mathrm{t}} \text { if } s t=1 \\
\mu_{2}+\sigma_{2} \varepsilon_{\mathrm{t}} \text { if } s t=2
\end{array}\right.
$$

where $y_{t}$ denotes the change of log in exchange rate returns, at period $t$ and the sample mean, $\mu$ and sample variance, $\sigma$ are ruled by an unobserved state variable, $S t \in\{1,2, \ldots . k\}$, where $S_{t}=k$ denotes a period of being in state $k, \varepsilon_{t}$ is the white noise error term. The evolution of the state variable from one regime to another regimes depends upon the transitional probabilities, where Regime 1 or $s_{t}=1$ is a period of downtrend of exchange rates associated with a negative mean change, and Regime 2 or $s_{t}=2$ is a period of uptrend of exchange rates corresponding to a positive mean change. In this study, $k=2$ is used and the state variable of $S_{t}$ will follow the ergodic first order Markov process as:

$$
P_{i j}=\operatorname{Pr}\left(S_{t}=j \mid S_{t-1}=i\right) \forall i, j=1,2^{\sum_{i=1}^{2} \rho_{i j}}=1
$$

where the $P_{i j}=\operatorname{Pr}\left(S t=j \mid S_{t-1}=i\right)$ denotes the probability that the process is in state $j$ at time $t$ given that it had been in state $i$ at the previous period, and $\sum j p_{i j}=1$. The transition probabilities in matrix $\mathrm{P}$ can be presented as follows:

$$
\begin{gathered}
\left.P=\begin{array}{ll}
\mathrm{P}(\mathrm{St}=1 \mid \mathrm{St}-1=1) & \mathrm{P}(\mathrm{St}=2 \mid \mathrm{St}-1=1) \\
\mathrm{P}(\mathrm{St}=1 \mid \mathrm{St}-1=2) & \mathrm{P}(\mathrm{St}=2 \mid \mathrm{St}-1=2)
\end{array}\right]=\left[\begin{array}{cc}
P_{11} & 1-P_{11} \\
1-P_{22} & P_{22}
\end{array}\right] \\
=\left[\begin{array}{ll}
P_{11} & P_{12} \\
P_{21} & P_{22}
\end{array}\right]
\end{gathered}
$$

Note that $\quad \mathrm{P}_{11}+\mathrm{P}_{12}=1$ and $\mathrm{P}_{21}+\mathrm{P}_{22}=1$, where

$\mathrm{P}_{11}=$ The probability of the downtrend of exchange rates remain unchanged

$\mathrm{P}_{12}=$ The probability of the downtrend of exchange rates shifting to the uptrend of exchange rates

$\mathrm{P}_{21}=$ The probability of the uptrend of exchange rates shifting to the downtrend of exchange rates

$\mathrm{P}_{22}=$ The probability of the uptrend of exchange rates remain unchanged

For the case of two regimes, the process $h$ periods later will be in regime 1 with probability $\pi_{1}=\operatorname{Pr}\left(S_{t}=1\right)$ $\Psi \mathrm{t})$ and regime 2 with probability $\pi_{2}=\operatorname{Pr}\left(\mathrm{S}_{\mathrm{t}}=2 \mid \Psi \mathrm{t}\right)$, whereas $\pi_{1}$ and $\pi_{2}$ are stable-state probabilities with time variants.

\subsection{The smoothed and filtered probabilities for Markov switching}

Using $\Psi_{t-1}=\left\{y_{1} \ldots \ldots y_{t-1}\right\}$, we calculated the smoothed probabilities:

$$
\begin{gathered}
P\left[s_{t}=j \mid \Psi_{T}\right]=\sum_{s_{k=1}}^{2} P\left[s_{t}=j, s_{t-1}=i \mid \Psi_{T}\right] \\
=\frac{P\left[s_{t+1}=k \mid \Psi_{T}\right] P\left[s_{t=j} \mid \Psi_{t}\right] P\left[s_{t+1}=k \mid s_{t}=j\right]}{P\left[s_{t-1}=k \mid \Psi_{t}\right]} \text { for } t=T-1, T-2, \ldots, 1
\end{gathered}
$$

In addition, $P\left[s_{T} \mid \Psi_{T}\right]$ in the last iteration of filter is calculated.

\subsection{The Markov switching GARCH model}

In general, the Markov switching GARCH model can be written as:

$$
\operatorname{rt} \mid \Omega \mathrm{t}-1 \sim\left\{\begin{array}{cc}
f\left(\theta_{t}^{(1)}\right) & w . P_{*} P_{1, t} \\
f\left(\theta_{t}^{(2)}\right) & w \cdot P_{*}\left(1-P_{1, t}\right)
\end{array}\right.
$$

where $\mathrm{f}($.$) represent possible conditional distribution such as normal, student's \mathrm{t}$ or generalized normal $\theta_{t}^{(1)}$

distribution, is denoted as vector of parameters in the i-th regime with distribution $P_{l, t}=\operatorname{Pr}\left[\mathrm{S}_{\mathrm{t}}=1 \mid \Omega_{t-1}\right]$, 
and is also known as the ex-ante probability and $\Omega$ t- 1 is the information set at time $t-1$. The vector of timevarying parameters can be decomposed into three components as:

$$
\theta_{t}^{(i)}=\left(\mu_{t}^{(\mathbb{d})}, h_{t}^{(\mathbb{D})}, v_{t}^{(\mathbb{D})}\right)
$$

where, ${ }^{(\mathbb{D})} \equiv E\left(r_{\mathrm{t}} \mid \Omega_{\mathrm{t}-1}, s_{\mathrm{t}}=i\right)$ is the conditional mean, $h_{\mathrm{t}}^{(\mathbb{D})} \equiv \operatorname{Var}\left(r_{\mathrm{t}} \mid \Omega_{\mathrm{t}-1}\right)$ is the conditional variance, and $v_{t}^{(i)}=$ the shape parameter of the conditional distribution. Markov switching GARCH consists of four elements; conditional mean, conditional variance, regime process and conditional distribution. The conditional mean equation can be modelled simply as constant mean, AR (1) and AR (2) components:

$$
\left\{\begin{array}{c}
r_{\mathrm{t}}^{(i)}=\mu^{(i)}+\varepsilon_{t}^{(i)} \\
r_{\mathrm{t}}^{(i)}=\mu^{(i)}+\varphi_{1}^{(i)} r_{\mathrm{t}-1}^{(i)}+\varepsilon_{\mathrm{t}}^{(i)} \\
\left.r_{\mathrm{t}}^{(i)}=\mu^{(i)}+\varphi_{1}^{(i)} r_{\mathrm{t}-1}+\varphi_{2}^{(i)}\right)_{\mathrm{t}-1}+\varepsilon_{\mathrm{t}}^{(i)}
\end{array}\right.
$$

where, $i=$ the regime $(i=1$ or 2$),{ }^{\varepsilon_{t}^{(i)}}=\eta_{t}^{(i)} \sqrt{h_{t}^{(i)}} \eta_{t}^{(i)}=$ a zero mean, unit variance process.

The conditional variance of the model can be expressed as:

$$
h_{t}^{(\mathrm{di})}=\alpha_{0}^{(\mathrm{d})}+\alpha_{1}^{(\mathrm{d})} \varepsilon_{\mathrm{t}-1}^{(\mathrm{di})}+\beta_{1}^{(\mathrm{d})} h_{\mathrm{t}-1}
$$

where $\mathrm{h}(\mathrm{t}-1)$ is a state-independent average of past conditional variance which is infeasible. The conditional variance depends on the observable $\Omega \mathrm{t}-1$, the current regime $\mathrm{S}_{\mathrm{t}}$, which determines all the parameters, and also on all past states, $\mathrm{S}_{\mathrm{t}-1.1}$ The probabilities on Markov switching GARCH can be calculated as:

$$
\begin{aligned}
& \widetilde{p_{\pi} . t}=\operatorname{Pr}\left(S_{t}=j \mid S_{t+1}=i, \zeta_{t-1}\right)=\frac{\left.p_{i j} \operatorname{Pr}\left(s_{t}=j\right] \zeta_{t-1}\right)}{\operatorname{Pr}\left(s_{t+1}=i \mid \zeta_{t-1}\right)} \\
& =\frac{P_{j i} P_{j . t}}{P_{i . t+1}}
\end{aligned}
$$

\subsection{Transition probabilities for Markov switching GARCH}

The main feature of this model is the ability for some or all parameters of the model to switch across different regimes, controlled by a state variable, $\mathrm{S}_{\mathrm{t}}$. The state variable is assumed to progress according to a firstorder Markov chain process, with transition probability, $\operatorname{Pr}\left(\mathrm{S}_{\mathrm{t}}=\mathrm{j} \mid \mathrm{S}_{\mathrm{t}-1}=\mathrm{i}\right)=\mathrm{P}_{\mathrm{ij},}$. This transition probability indicates the probability of switching from state $i$ at time $t-l$ to state $j$ at $t$. All probabilities are grouped together into a transition matrix. In this study, two regimes are considered and the matrix can be presented as follows:

$$
\begin{aligned}
P=\left[\begin{array}{ll}
\mathrm{P}(\mathrm{St}=1 \mid \mathrm{St}-1=1) & \mathrm{P}(\mathrm{St}=2 \mid \mathrm{St}-1=1) \\
\mathrm{P}(\mathrm{St}=1 \mid \mathrm{St}-1=2) & \mathrm{P}(\mathrm{St}=2 \mid \mathrm{St}-1=2)
\end{array}\right] & =\left[\begin{array}{cc}
P_{11} & 1-P_{11} \\
1-P_{22} & P_{22}
\end{array}\right] \\
& =\left[\begin{array}{ll}
P_{11} & P_{12} \\
P_{21} & P_{22}
\end{array}\right]
\end{aligned}
$$

This yield,

$$
P=\left[\begin{array}{ll}
P_{11} & P_{12} \\
P_{21} & P_{22}
\end{array}\right]=\left[\begin{array}{cc}
p & 1-q \\
1-p & q
\end{array}\right]
$$

The unconditional probability of being in state $\mathrm{S}_{\mathrm{t}}=1$ is given by $\pi_{1}=(1-\mathrm{q}) /(2-\mathrm{p}-\mathrm{q})$.

In this study, the parameters of both models were estimated using Maximum Likelihood (MLE). The best model was selected based on two specification measures, log-likelihood values ( $\log L$ ), Akaike Information Criteria (AIC) and Bayesian Information Criteria (BIC) criteria.

\section{RESULTS AND ANALYSIS}

Tables 1 and 2 show the parameter estimates for CNY, JPY, KRW, SGD and the USD against MYR, respectively, using the M-S and M-S GARCH models. All estimated coefficients are statistically significant at conventional significant levels. 
Table 1. Parameter estimates for Markov switching model

\begin{tabular}{|c|c|c|c|c|c|c|c|c|c|c|}
\hline \multirow{2}{*}{$\begin{array}{l}\text { Currencies } \\
\text { Regime }\end{array}$} & \multicolumn{2}{|c|}{ CNYMYR } & \multicolumn{2}{|c|}{ JPNMYR } & \multicolumn{2}{|c|}{ KRWMYR } & \multicolumn{2}{|c|}{ SGDMYR } & \multicolumn{2}{|c|}{ USDMYR } \\
\hline & 1 & 2 & 1 & 2 & 1 & 2 & 1 & 2 & 1 & 2 \\
\hline Estimate & -0.206 & -0.572 & 2.378 & -9.606 & -0.743 & 0.446 & 0.4616 & 0.596 & 0.299 & -0.111 \\
\hline Std error & 0.527 & 0.851 & 1.333 & 1.612 & 1.116 & 1.100 & 0.3399 & 0.642 & 0.902 & 0.458 \\
\hline $\begin{array}{l}\operatorname{Pr}(>|t|) \\
\text { return_1: }\end{array}$ & 0.697 & 0.501 & 0.074 & 0.000 & 0.506 & 0.685 & 0.175 & 0.353 & 0.740 & 0.808 \\
\hline Estimate & -0.122 & 1.104 & 0.057 & 0.877 & -0.199 & 0.372 & -0.116 & 2.078 & 1.341 & -0.128 \\
\hline \multirow[t]{2}{*}{$\operatorname{Pr}(>|t|)$} & 0.221 & 0.001 & 0.738 & 0.015 & 0.010 & 0.118 & 0.268 & 0.000 & 0.000 & 0.10 \\
\hline & \multicolumn{10}{|c|}{ Regime } \\
\hline $\begin{array}{c}\text { Transition } \\
\text { Probabilities: }\end{array}$ & 1 & 2 & 1 & 2 & 1 & 2 & 1 & 2 & 1 & 2 \\
\hline Regime 1 & 0.0001 & 0.9999 & 0.5971 & 0.4029 & 0.0535 & 0.9465 & 0.5870 & 0.4130 & 0.1807 & 0.8193 \\
\hline Regime $2(\pi 2)$ & \multicolumn{2}{|c|}{0.5553} & \multicolumn{2}{|c|}{0.2950} & \multicolumn{2}{|c|}{0.6919} & \multicolumn{2}{|c|}{0.3273} & \multicolumn{2}{|c|}{0.4503} \\
\hline $\begin{array}{l}\text { Expected } \\
\text { Duration }\end{array}$ & 1.80 & 2.25 & 3.39 & 1.42 & 1.45 & 3.25 & 3.06 & 1.49 & 2.22 & 1.82 \\
\hline AIC & \multicolumn{2}{|c|}{239.4522} & \multicolumn{2}{|c|}{287.6464} & \multicolumn{2}{|c|}{264.2710} & \multicolumn{2}{|c|}{190.1288} & \multicolumn{2}{|c|}{247.6312} \\
\hline $\mathrm{BIC}$ & \multicolumn{2}{|c|}{261.9055} & \multicolumn{2}{|c|}{310.0997} & \multicolumn{2}{|c|}{286.7243} & \multicolumn{2}{|c|}{212.5821} & \multicolumn{2}{|c|}{270.0845} \\
\hline Log Lik & \multicolumn{2}{|c|}{-115.7261} & \multicolumn{2}{|c|}{-139.8232} & \multicolumn{2}{|c|}{-128.1355} & \multicolumn{2}{|c|}{-91.06439} & -11 & 156 \\
\hline
\end{tabular}

Table 2. Parameter estimates for Markov switching GARCH model

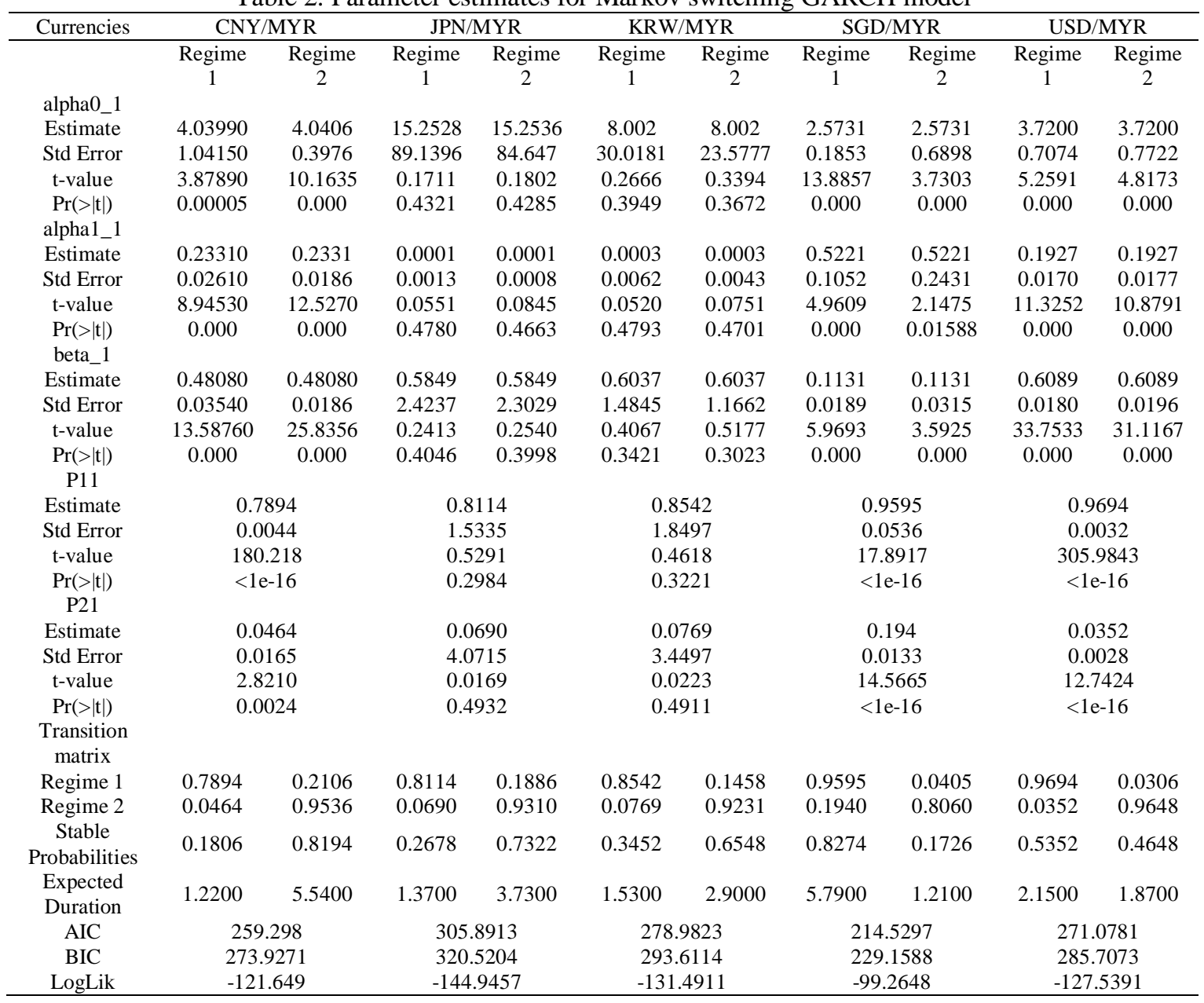


From Table 1, the transition probabilities explain on persistency of each regime. It is shown that, CNY/MYR has high persistence on Regime 2, with a probability value equals 0.999 , indicating that when the process is in Regime 1, there is very high probability that it switches to Regime $2,\{\mathrm{p}(\mathrm{St}=2 \mid \mathrm{St}-1=1)\}$ by almost $100 \%$. The average duration of two regimes are 1.80 and 2.25 months. The stable probabilities of Regime $1, \pi 1$ and Regime 2, $\pi 2$ are 0.4447 and 0.5553 , respectively. The same goes for KRW/MYR, where the transition probabilities recommend Regime 2 as highly persistent. When the process is in Regime 1 , there is a high probability that it switches to Regime 2 by 0.9645 . The average duration of two regimes are 1.45 and 3.25 months. The stable probabilities of Regime $1(\pi 1)=0.3081$ and Regime $2(\pi 1)=0.6919$. This is followed by USD/MYR, in which the switch from Regime 1 to Regime 2, is also highly persistent with probability value of 0.8193 . The average duration of two regimes were 2.22 and 1.82 months. The stable probabilities of Regime $1(\pi 1)=0.5497$ and Regime $2(\pi 1)=0.4503$. In contrast, the transition probabilities of JPY/MYR and SGD/MYR show low persistent for Regime 2. The probability that both currencies switch to Regime 2 are very low, by 0.4029 and 0.4130 , respectively. For JPY/MYR, the average duration of two regimes is 3.39 and 1.42 months. The stable probabilities of Regimes 1 and 2 are 0.7050 and 0.2950 , respectively. In addition, SGD/MYR's average duration of two regimes is 3.06 and 1.49 months. The stable probabilities of Regimes 1 and 2 are 0.6727 and 0.3273 , respectively.

From Table 2, the transition probabilities for all CNY/MYR, JPN/MYR, KRW/MYR, SGD/MYR and USD/MYR show high persistent for Regime 1. The highest probability is for USD/MYR and SGD/MYR by the values of 0.9694 and 0.9595 , respectively. This is followed by KRW/MYR and JPN/MYR with probabilities of 0.8542 and 0.8114 , respectively. The lowest is CNY/MYR with a probability value of 0.7894. The results indicate that all parameter estimates are significant except for JPY/MYR. The best model in this study is Markov switching due to its lowest AIC and BIC values, and the highest log-likelihood values as compared to Markov switching GARCH.

\section{CONCLUSION}

The aim of this paper is to model the foreign exchange rates and its returns for five different currencies against the Malaysian Ringgit using two models, Markov switching and Markov switching GARCH. The results show that the Markov switching model is better than Markov switching GARCH due to the lowest AIC and BIC values and the highest log-likelihood value. The results indicate that based on Markov switching model, each of CNY/MYR, KRW/MYR and USD/MYR is highly persistent in Regime 2. On contrary, JPY/MYR and SGD/MYR, show high persistency in Regime 1. This study can be extended further by considering other factors such as interest rate, inflation rate, current-account deficits, public debt, political stability and economic performance within a regime-switching framework. Moreover, it is recommended to employ other types of Markov regime switching model such MRS-GARCH-N, MRS-GARCH-t and MRSGARCH-GED for a more thorough comparison by incorporating the presence of outliers in the models.

\section{ACKNOWLEDGEMENT}

The authors would like to thank the Ministry of Education Malaysia (MOE) and Malaysia Institute of Transport of Universiti Teknologi MARA, Malaysia for supporting this project.

\section{REFERENCES}

[1] L., Linawati, M., Sudarma, I.P.O., Wisnawa, "Forecasting rupiah exchange rate with learning vector quantization neural network," Indonesian Journal of Electrical Engineering and Computer Science (IJEECS), vol. 18, no. 1, pp. 24-31, 2020.

[2] A. Hakim, M. McAleer, "Modelling the interactions across international stock, bond and foreign exchange markets," Applied Economics, vol. 42, no. 7, pp. 825-850, 2010.

[3] I. S., Chaudhry, et al., "Foreign exchange reserves and inflation in Pakistan: Evidence from ARDL modelling approach," International Journal of Economics and Finance, vol. 3, no. 1, pp. 69-76, 2011.

[4] E. A. Abdullah, et al., "Modelling volatility of Kuala Lumpur Composite Index (KLCI) using SV and GARCH models," Indonesian Journal of Electrical Engineering and Computer Science (IJEECS), vol. 13, no. 3, pp.1087-1094, 2019.

[5] H., Mohd Rahman et al., "Forecasting ASEAN countries exchange rates using auto regression model based on triangular fuzzy number," Indonesian Journal of Electrical Engineering and Computer Science (IJEECS), vol. 14, no. 3, pp. 1525-1532, 2019.

[6] R., Rassetiadi, Suharjito, "Foreign exchange prediction based on indices and commodities price using convolutional neural network," Indonesian Journal of Electrical Engineering and Computer Science (IJEECS), vol. 18, no. 1, pp. 494-501, 2020. 
[7] C., Engel \& J. D. Hamilton, "Long swings in the dollar: Are they in the data and do markets know it?," The American Economic Review, pp. 689-713,1990.

[8] Y. W., Cheung, \& K. S. Lai, "Long memory and nonlinear mean reversion in Japanese yen-based real exchange rates," Journal of International Money and Finance, vol. 20, no. 1, pp. 115-132, 2001.

[9] C., Engel, "Can the Markov switching model forecast exchange rates?" Journal of international economics, vol. 36, no. $1-2$, pp.151-165, 1994.

[10] C., Engel, C. S., Hakkio, "The distribution of exchange rates in the EMS," International Journal of Finance \& Economics, vol. 1, no. 1, pp.55-67, 1996.

[11] I.W., Marsh, "High-frequency Markov switching models in the foreign exchange market," Journal of Forecasting, vol. 19, no. 2, pp.123-134, 2000.

[12] N., Bollen, et al, "Regime switching in foreign exchange rates: Evidence from surrency option prices," Journal of Econometrics, vol. 94, pp. 239-276, 2000.

[13] C., Walid, et al, "Stock market volatility and exchange rates in emerging countries: A Markov-state switching approach," Emerging Markets Review, vol. 12, no. 3, pp.272-292, 2011.

[14] U. M., Bergman, J., Hansson. "Real exchange rates and switching regimes," Journal of International Money and Finance, vol. 24, no. 1, pp.121-138, 2005.

[15] M. T., Ismail, Z., Isa, "Detecting regime shifts in Malaysian exchange rates," Malaysian Journal of Fundamental and Applied Sciences, vol. 3, no. 2, 2014.

[16] M.A.A. Rahim, et al., "Variance Targeting Estimator for GJR-GARCH under Model's Misspecification," Sains Malaysiana, vol. 47, no. 9, pp. 2195-2204, 2018.

[17] M.A.A. Rahim, et al., "Impact of Univariate Error Distribution Assumption toward Multivariate GARCH Parameter Estimation Performance,” Int. J. Advance Soft Compu. Appl, vol. 8, no. 1, 2016.

[18] R., Casarin, et al., "Uncertainty through the lenses of a mixed-frequency Bayesian panel Markov-switching model," The Annals of Applied Statistics, vol. 12, no. 4, pp.2559-2586, 2018.

[19] J., Cai, "A Markov Model of Switching-Regime ARCH," Journal of Business \& Economic Statistics, vol. 12, no. 3, pp.309-316, 1994

[20] J. D., Hamilton, R., Susmel, "Autoregressive conditional heteroskedasticity and changes in regime," Journal of Econometrics, vol. 64, pp.307-333, 1994

[21] J. D.,Hamilton, "A new approach to the economic analysis of nonstationary time series and the business cycle," Econometrica, vol. 57, pp. 357-384, 1989.

[22] J. D., Hamilton, "Time series analysis," Princeton: Princeton University Press, 1994.

[23] A., Aue et al., "Functional generalized autoregressive conditional heteroskedasticity," Journal of Time Series Analysis, vol. 38, vol. 1, pp.3-21, 2017.

[24] P., Ekaterini, P., Theologos, "Regime-switching models for exchange rates," The European Journal of Finance, vol. 21, no. 12, pp.1023-1069, 2015.

[25] J., Stillwagon, P., Sullivan, "Markov switching in exchange rate models: will more regimes help?" Empirical Economics, pp. 2019.

\section{BIOGRAPHIES OF AUTHORS}
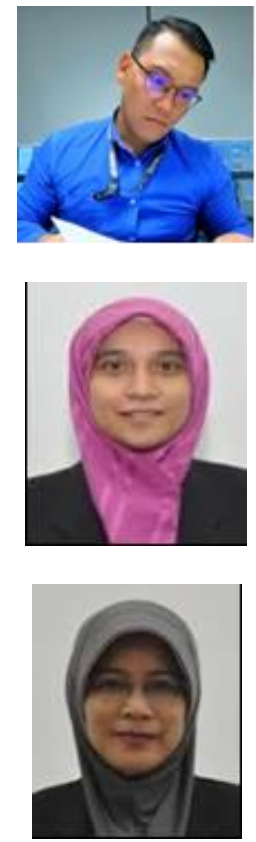

Mohd Azizi Amin Nunian, He is a post graduate student in Master of Quantitative Sciences in Faculty of Computer and Mathematical Sciences, Universiti Teknlogi MARA, Shah Alam

Siti Meriam Zahari, She is a Senior Lecturer in Centre of Statistics and Decision Science Studies in Faculty of Computer and Mathematical Sciences, Universiti Teknlogi MARA, Shah Alam. Her expertise is in Econometrics and Time Series.

S. Sarifah Radiah Shariff, She is a Senior Lecturer in Centre of Statistics and Decision Science Studies in Faculty of Computer and Mathematical Sciences, Universiti Teknlogi MARA, Shah Alam. Her expertise is in Supply Chain and Logistics Modelling. Currently she is attached to Malaysia Institut e of Transport, UiTM. 